\title{
FORECASTING OF WELDING DISTORTIONS IN LARGE-SIZED STRUCTURES
}

\author{
1'Janusz PIKUŁA, ${ }^{1}$ Tomasz PFEIFER \\ ${ }^{1}$ Łukasiewicz Research Network - Institute of Welding, Gliwice, Poland, EU, janusz.pikula@is.gliwice.pl
}

https://doi.org/10.37904/metal.2020.3524

\begin{abstract}
The prevention of welding distortions is one of the most important and, at the same time, most difficult issues in welding engineering. The above-named distortions result from the combined effect of the shrinkage of solidifying weld metal and the shrinkage occurring in the partially melted zone (primarily in the HAZ). Welding distortions often preclude the obtainment of proper joints in large-sized elements and, could even lead to the disqualification of the final product failing to satisfy related standard requirements concerning maximum distortion values. In spite of extensive research focused on welding distortions, they remain the primary issue accompanying the making of steel structures. Various industrial sector organisations express their need for solutions making it possible to forecast the presence of welding distortions. The possibility of forecasting the probable structure imperfections during assembly and the prevention of such imperfections as early as at the design stage and when scheduling assembly make it possible to reduce costs and delays resulting from the removal of distortions. The use of appropriate methods can reduce welding distortions yet it does not ensure their entire elimination. Engineering practice relies on analytical methods involving calculations of total distortions present in elements of welded structures having one and two-sided longitudinal welds, transverse distortions generated during the butt welding of sheets as well as local distortions generated as a result of the loss of stability of thin-walled welded structures. Knowledge concerning possible welding distortions can also be obtained by performing FEM-based numerical analyses concerned with the welding of structures.
\end{abstract}

Keywords: Welding, welding distortions, hull section, shipbuilding industry, FEM

\section{INTRODUCTION}

The prevention of welding distortions is one of the most important and, at the same time, most difficult issues in welding engineering. The above-named distortions result from the combined effect of the shrinkage of solidifying weld metal and the shrinkage occurring in the partially melted zone (primarily in the HAZ), which, in turn, result from plastic strains and phase transformations. Welding distortions often preclude the obtainment of proper joints in large-sized elements and could even lead to the disqualification of the final product failing to satisfy related standard requirements concerning maximum distortion values $[1,4]$.

Welding distortions occur along with stresses generated in the welded joint area as well as in areas located farther from the joint. Such stresses can be detrimental to the welded structure in terms of its load-carrying capacity as they may combine with externally-induced stresses. The above-named stresses could reduce the time of safe operation of the structure subjected to fatigue or trigger the formation of brittle cracks at the initial stage of structure operation. In spite of extensive research focused on welding distortions, they remain the primary issue accompanying the making of steel structures. Various industrial sector organizations express their need for solutions making it possible to forecast the presence of welding distortions in large-sized steel structures as well as enabling the determination of the effect of appropriate methods (e.g. fixing clamps, counter-distortions) aimed to limit the formation of distortions [3-6].

The possibility of forecasting the probable structure imperfections during assembly and the prevention of such imperfections as early as at the design stage and when scheduling assembly make it possible to reduce costs 
and delays resulting from the removal of distortions. The use of appropriate methods can reduce welding distortions, yet it does not ensure their entire elimination. For this reason, the forecasting of distortion-triggered consequences is of great importance. Knowledge about possible structure defects when designing the process of assembling and that of welding can be utilized to prevent the occurrence of unwanted results through, among other things, providing allowances in elements being welded. Engineering practice relies on analytical methods involving calculations of total distortions present in elements of welded structures having one and two-sided longitudinal welds, transverse distortions generated during the butt welding of sheets/plates (and surfacing) as well as local distortions generated as a result of the loss of stability of thin-walled welded structures. Knowledge concerning possible welding distortions can also be obtained by performing FEM-based numerical analyses concerned with the welding of structures [5-9]. The issue of welding distortions is also present in the prefabrication of the hull structure, where the generation of distortions (if any) is additionally affected by the welding of stiffening elements (representing 1st and 2nd order) to flat sections. In addition, welding distortions could also result from the welding of complex sections composed of flats and/or trough sections such as deep tanks in the mid-ship, sections of superstructures as well as the double bottom of the bow and stern peak $[10,11]$.

\section{TEST OBJECTS}

The test objects included a flat section and stiffeners made of ship plate grade $A$ in accordance with ASTM A131. The dimensions of the elements, the location of the stiffeners and the welding sequence are presented in Figure 1. In each case, the welding process was initiated on the same side of the plate. The section was placed on a $15 \mathrm{~mm}$ thick steel table. The welding linear energy amounted to $7.45 \mathrm{~kJ} / \mathrm{cm}$ whereas the welding rate amounted to $45 \mathrm{~cm} / \mathrm{min}$. The welding process was performed using flux-cored wire $\varnothing 1.2 \mathrm{~mm}$ grade Outershield 71M-H (Lincoln Electric).

a)
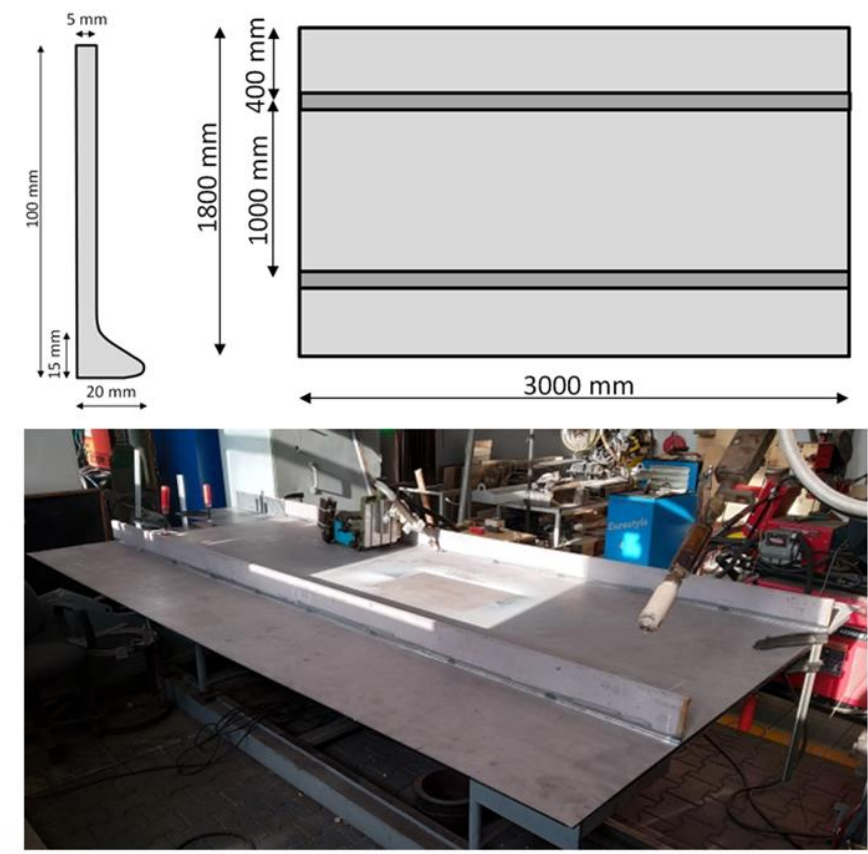

b)

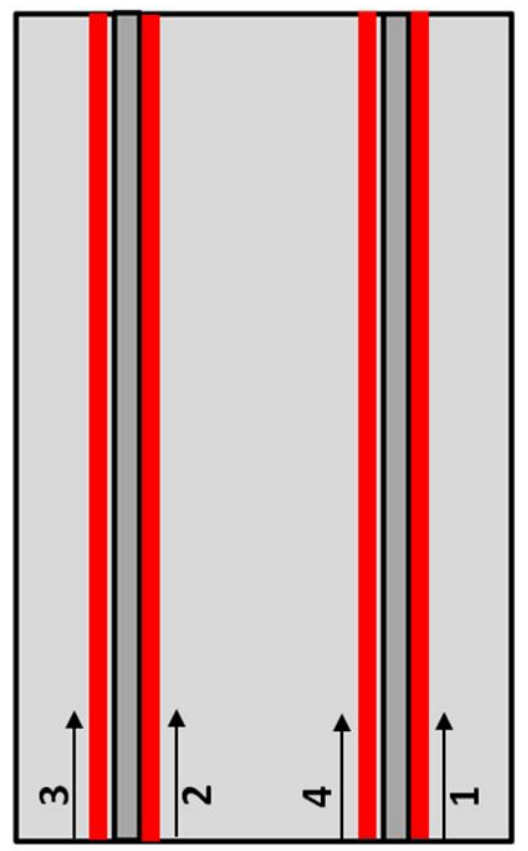

Figure 1 a) Dimensions of the flat section and the arrangement of the stiffeners of the first grade, b) welding sequence

Measurements of welding distortions, focused on a fragment of the element subjected to welding, were performed using a Dantec Dynamics Q-400 Multicamera Digital Image Correlation system and 3 cameras 5MPx (Figure 2). The first stage involved the measurement of the plate before welding. The second 
measurement was carried out after the completion of the welding process and the cooling of the element. The difference between the measurement results obtained before and after welding constituted the value of displacements.
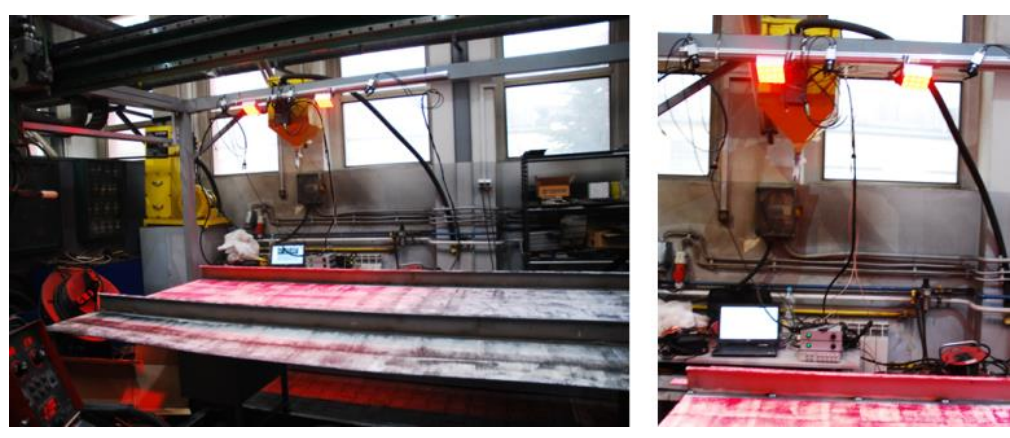

Figure 2 Fragment of the flat section and the stiffener used in the measurements of welding distortions and the Dantec Dynamics Q-400 Multicamera Digital Image Correlation system

The visual assessment and the measurements involving the use of the optical system revealed the corrugation of the flat section (Figure 3). The maximum value of displacement, amounting to $14.1 \mathrm{~mm}$, was observed in the corner of the plate. The measurements focused on the analysis of the displacements in the direction perpendicular to the surface of the flat section. The reason for the aforesaid analytical approach resulted from the significant value of the above-named displacements in comparison with the values of the displacements in the remaining directions.
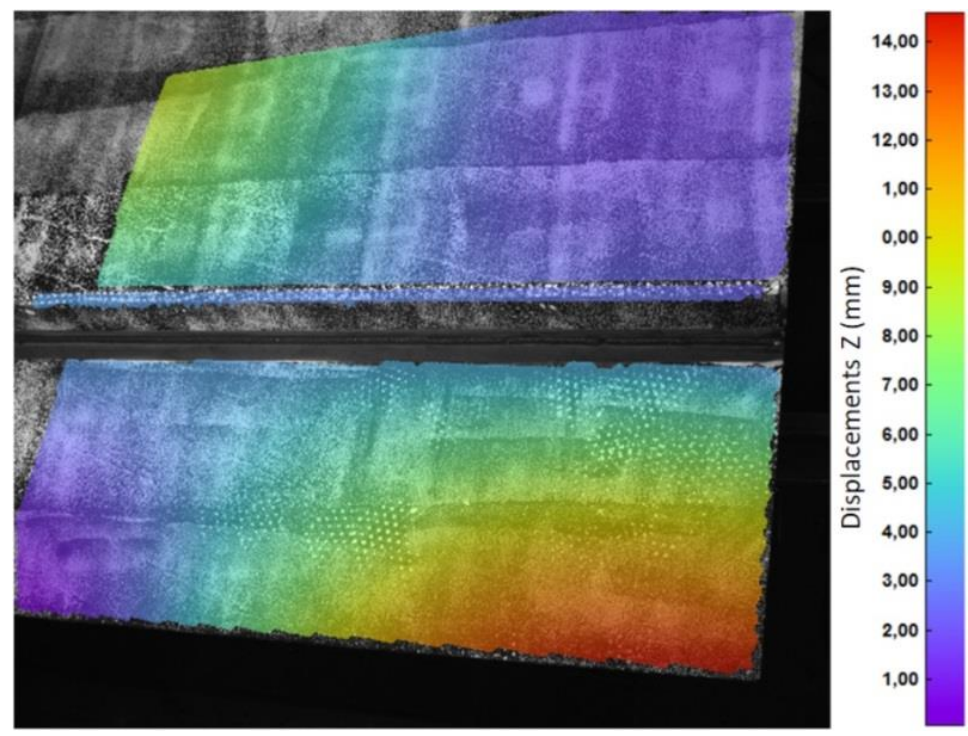

Figure 3 Z-displacement (perpendicular to the flat section) field of the fragment of the welded elements

\section{FEM NUMERICAL ANALYSIS}

The approach used for the modelling of the welding process and applied in the FEM model was based on the "Imposed Thermal Cycle" method implemented in the SYSWELD software. In the aforesaid method, a specific fragment of the welded joint is subjected to the effect of the welding thermal cycle. In the above-named FEM model, the weld is divided into segments subjected sequentially to the thermal cycle determined using the model with the moving Goldak heat source [12]. The modelling of the geometry of the element subjected to welding involved the use of shell elements based on midsurfaces. The flat section and the stiffeners of the first order were modelled using shell elements based on midsurfaces. In turn, the welding process was modelled 
using the "Imposed Thermal Cycle" method by dividing the weld into segments sequentially subjected to welding thermal cycles; the weld was modelled using shell elements. Preseted boundary conditions aimed to model the section restraint conditions during the actual welding process. The flat section was restrained using a welding clamp and placed on a steel plate. The model involved the application of the boundary conditions of symmetry and restrains in all directions representing the effect of the welding clamp on the system (Figure 4). The effect of the table on the element during welding was modelled by means of the "stop" boundary condition, preventing the displacement of the nodes in the y-direction (normal in relation to the section). The model also involved taking into consideration the effect of gravity force.

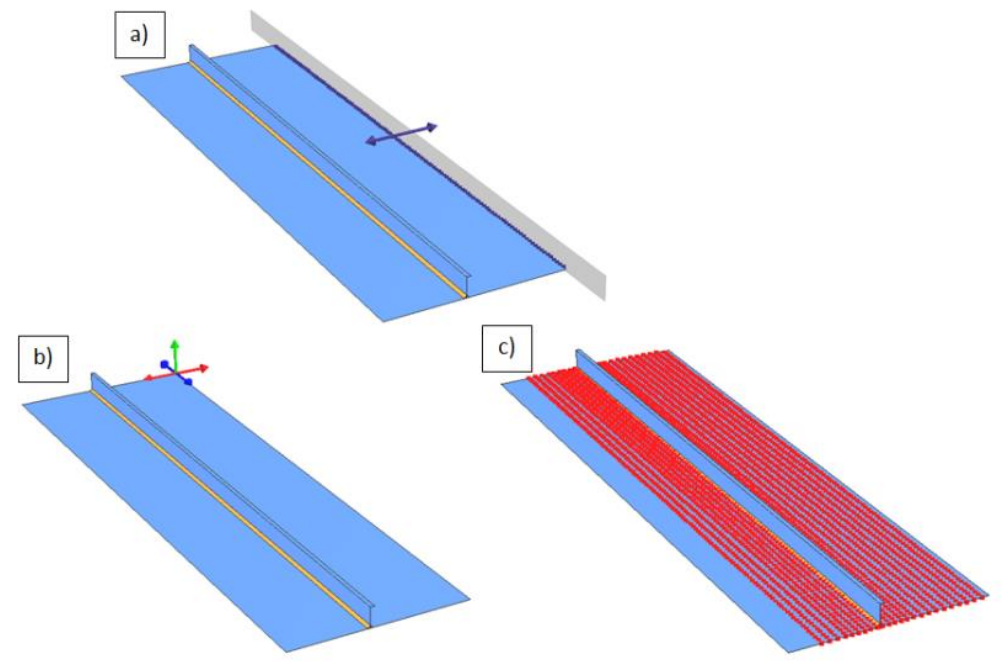

Figure 4 Preset boundary conditions a) of symmetry, b) restraint in all directions and c) "stop" boundary condition

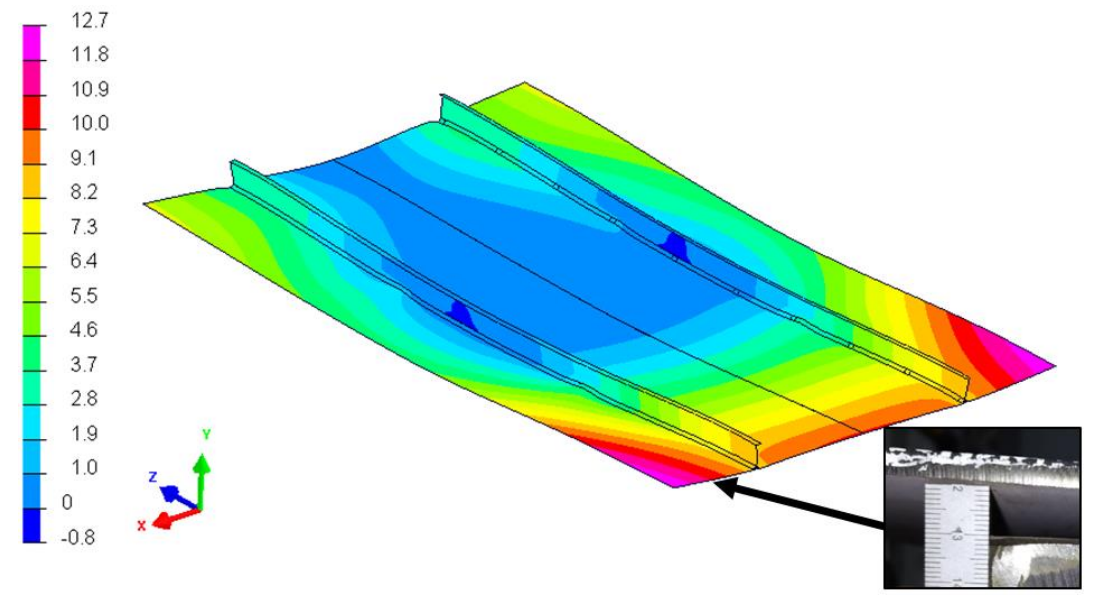

Figure 5 Field of displacements in the normal direction in relation to the section surface, $\mathrm{mm}$

\section{TEST RESULTS}

The tests focused on the analysis of the displacements in the direction perpendicular to the surface of the flat section. The reason for such an approach resulted from the significant values of the above-named displacements in comparison with the values of the displacements in the remaining directions. Figure $\mathbf{5}$ presents the field of displacement in the normal direction in relation to the section subjected to welding. The maximum value of displacement amounted to $12.7 \mathrm{~mm}$. It was possible to observe the characteristic corrugation of the plate, similar to that presented in Figure 3. The FEM calculation results were compared with 
the values measured using the optical system (Figure 6) and a gap gauge (Table 1). The difference between the calculated displacement and the displacement measured using the optical system in points nos. 1 and 2 amounted to $11 \%$.
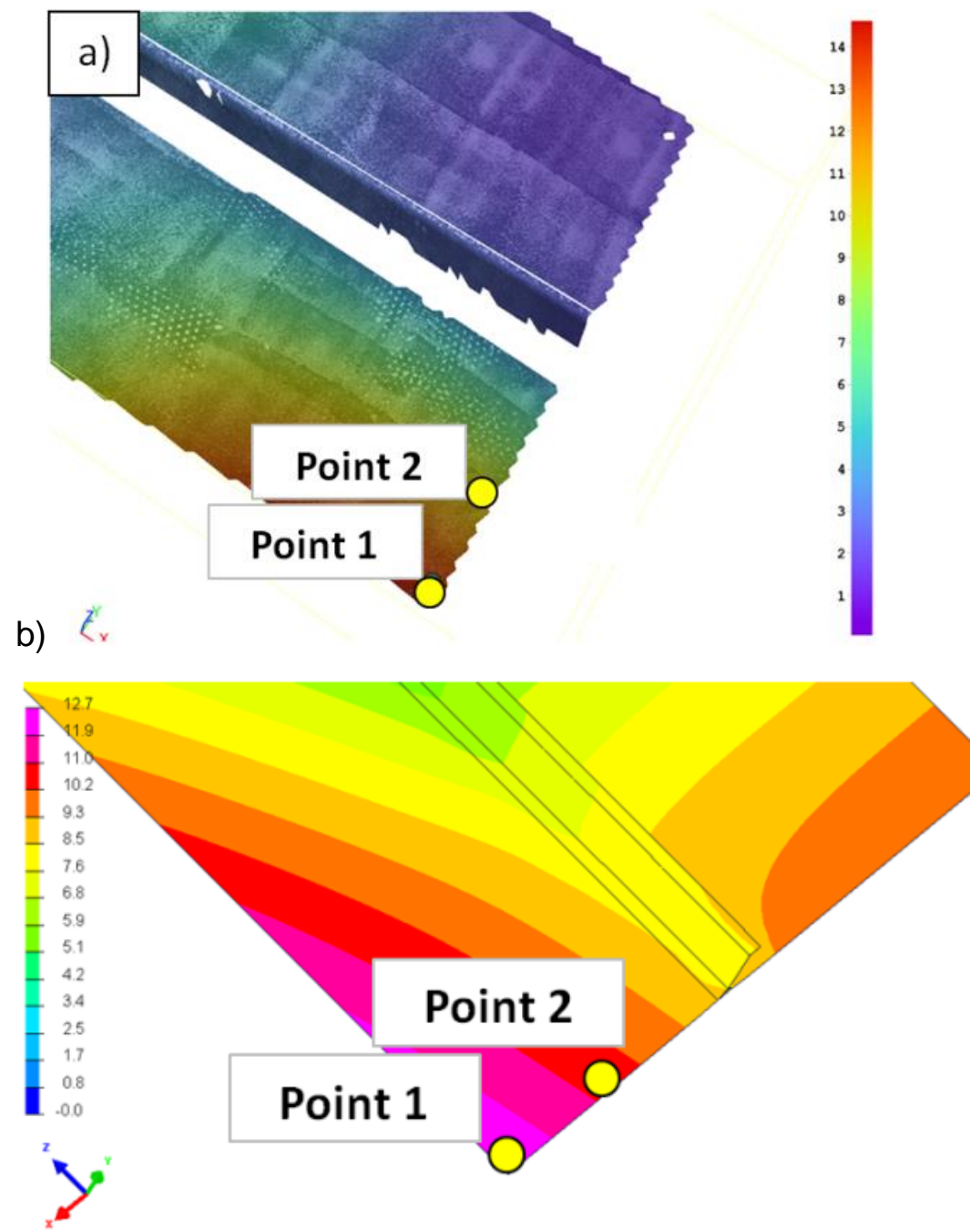

Figure 6 Displacement in the normal direction in relation to the section surface a) measurements of the actual element (performed using the optical system) and b) FEM calculation results

Table 1 Results of displacements in the normal direction in relation to the section surface in points 1 and 2 in accordance with Figure 6

\begin{tabular}{|c|c|c|}
\hline Point & $\begin{array}{c}\text { Optical system-based measurement results } \\
(\mathbf{m m})\end{array}$ & FEM calculation results (mm) \\
\hline 1 & 14.1 & 12.7 \\
\hline 2 & 9.1 & 10.1 \\
\hline
\end{tabular}

\section{CONCLUSIONS}

Because of their low rigidity, spatial-flat elements are particularly susceptible to welding distortions. In cases of large welded sheets/plates with stiffeners it is often necessary to make long welds, frequently resulting in shrinkage and, consequently, in the corrugation of a given element. 
The above-presented procedure used for the modelling of large-sized elements enables the obtainment of computational results consistent with those obtained in actual conditions. In comparison with the method based on the moving heat source, the application of the "Imposed Thermal Cycles" method (implemented in the SYSWELD software) in the FEM numerical model reduces time necessary to calculate welding distortions consistent with those observed in the actual welding process. The time of calculations can be additionally reduced (without compromising the correctness of calculation results) by applying thin (i.e. shell) elements in the FEM numerical model.

The method discussed in the article can be successfully applied in the forecasting of welding distortions in large-sized welded structures.

\section{ACKNOWLEDGEMENTS}

The above-presented work was performed using funds provided by the Ministry of Science and Higher Education in Poland, within the research work entitled Numerical FEM Analysis of Distortions of Spatial Flat Elements Used in Large-Sized Welded Structures.

\section{REFERENCES}

[1] OCHODEK, V., BOXAN, P. Numerical simulation of welding high carbon steel after SPD process. In METAL 2016: 25th International Conference on Metallurgy and Materials. Brno: TANGER, 2016, pp. 807-812.

[2] PIEKARSKA, W., SATERNUS, Z., KUBIAK, M., DOMAŃSKI, T., GOSZCZYŃSKA-KROLISZEWSKA, D., Computer Analysis of Stress and Deformations in Laser Welded T-joint at Different Inclinations of the Welding Source. In METAL 2017: 26th International Conference on Metallurgy and Materials. Brno: TANGER, 2017, pp. 1003-1008.

[3] KOWALSKI, D. Wpływ imperfekcji wykonawczych na stan naprężeń w płaszczu stalowego zbiornika walcowego o osi pionowej. PhD Thesis. Gdansk: Gdansk University of Technology, Faculty of Civil and Environmental Engineering, 2004.

[4] CORREIA, D.S., FERRARESI, V.A. Welding process selection through a double criteria: Operational costs and non-quality costs. Journal of Materials Processing Technology. 2007, vol. 184, pp. 47-55.

[5] WEGLOWSKI, M.St., ZEMAN, M., GROCHOLEWSKI, A. Effect of welding thermal cycles on microstructure and mechanical properties of simulated heat affected zone for a Weldox 1300 ultra-high strength alloy steel. Archives of Metallurgy and Materials. 2016, vol. 61, no. 1, pp. 127-132.

[6] RAKOCZY, Ł., Grudzień, M., TUZ, L., PAŃCIKIEWICZ, K., ZIELIŃSKA-LIPIEC, A. Microstructure and properties of a repair weld in a nickel based superalloy gas turbine component. Advances in Materials Science. 2017, vol. 17 no. 2, pp. 55-63.

[7] LI, Y., WANG, K., JIN, Y., XU, M., LU, H. Prediction of welding deformation in stiffened structure by introducing thermo-mechanical interface element. Journal of Materials Processing Technology. 2015, vol. 216, pp. 440-446.

[8] FRICKE, W., ZACKE, S. Application of welding simulation to block joints in shipbuilding and assessment of welding-induced residual stresses and distortions. International Journal of Naval Architecture and Ocean Engineerin. 2014, vol. 6, pp. 459-470.

[9] BARSOUM, Z., BHATTI, A.A., BALAWI, S. Computational weld mechanics - towards a simplified and cost effective approach for large welded structures. Procedia Engineering. 2015, vol. 114, pp. 62-69.

[10] FU, G., LOURENCO, M.I., DUAN, M., ESTEFEN, S.F. Influence of the welding sequence on residual stress and distortion of fillet welded structures. Marine Structures. 2016, vol. 46, pp. 30-55.

[11] PARK, J., AN, G. Prediction of the welding distortion of large steel structure with mechanical restraint using equivalent load methods. International Journal of Naval Architecture and Ocean Engineering. 2017, vol. 9, pp. 315-325.

[12] KIK, T., MORAVEC, J., NOVAKOVA, I. Application of Numerical Simulations on 10GN2MFA Steel Multilayer Welding. Springer Proceedings in Mathematics and Statistics, 2018, vol. 249, pp. 193-204. 